\title{
A Novel Method for the Deprotection of N-Boc-D-Glucosamine-Ac by Irradiation via Microwave
}

\author{
H. Bouleghlem, N. E. Aouf, and S. Zidane
}

\begin{abstract}
Since the microwave was used for the first time in 1986 in the field of the organic synthesis, the reactions assisted by microwaves are used more and more in the strategies of synthesis. It meets an interest growing because of its great effectiveness and its extreme profitability due to reduced reaction times, better outputs and obtaining purer products. Its particular use, was the subject of a method around whose developed a green chemistry. Several developed, he was devoted, and the last in date is a work C.O. Kappe in 2005 . Within the framework of this work, we will try to develop an aspect of the chemistry of the protective groupings: chimioselective protection deprotection of $N$-Boc-Glucosamine-Acyle by irradiation under domestic microwave. The usual spectroscopic methods $\left({ }^{1} H\right.$ NMR, IR and MS) were made profitable for elucidation synthesized structures.
\end{abstract}

Index Terms-Chimioselective, deprotection, glucosamine, irradiation, microwave, protection.

\section{INTRODUCTION}

Heterocycles are a class of compounds in which one or more carbon atom is replaced by a heteroatom such as oxygen, nitrogen, phosphorus, sulfur ... etc. The most common hetero rings containing nitrogen or oxygen.

Approximately two thirds of publications in chemistry concern heterocycles. A very large number of natural substances and therefore drugs are based of heterocyclic.

The heterocyclic's forms the basic skeleton for a wide variety of chemical compounds interest, biological, pharmacological and industrial [1], [2]. Note that two-thirds of the organic compounds known from the literature are heterocyclic [3], such as sugars which are organic molecules very widespread in the major cell types described: bacteria, and in the connective tissues and cell membranes of animals, vegetable cell.

These are compounds formed during photosynthesis. They are very important in the biological world. They are divided mainly of sugars or monosaccharides and osides (see Fig. 1).

Our interest is charged to aminomonosaccharides compounds (amino sugar). We conducted our research on (+)D-glucosamine hydrochloride, the $(+)$ - D- $\mathrm{GlcNH}_{2} . . \mathrm{HCl}$, is very known for its physiological role [4], [5].

Glucosamine is a carbohydrate of the family of osamines whose structure is based on glucose.

Manuscript received May 26, 2015; revised July 2, 2015.

H. Bouleghlem and N. E. Aouf are with Organic chemistry laboratory Applied (LCOA), Group of Chemistry Bioorganique Faculty of Science, Department of Chemistry. University Badji-Mokhtar 23000 Annaba, Algeria (e-mail: hocine_isc01@yahoo.fr, noureddineaouf@yahoo.fr).

S. Zidane is with Laboratory of Electrochemistry, Molecular Engineering and Catalysis Redox LEIMCR University F. ABBAS - 19000 Setif, Algeria (e-mail: zidanesabrina@yahoo.fr).
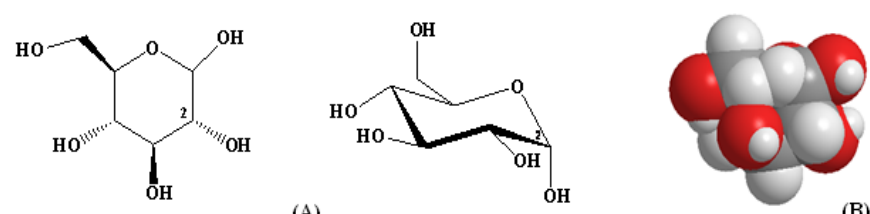

Fig. 1. (+) - D-glucopyranose : representations ( A) and hexagonal (B) 3D (red : oxygen; black : carbon; white : hydrogen) (Space Filling).

In the glucosamine molecule, the carbon at position 2 does not bear alcohol function but a primary amine function $\left(-\mathrm{NH}_{2}\right)$ oriented in the same way on the asymmetric carbon (see Fig. 2).
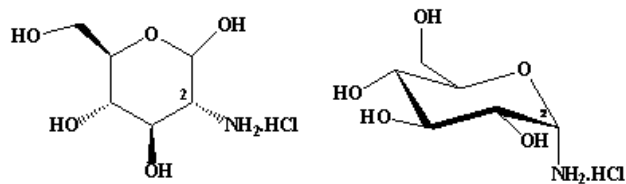

(A)

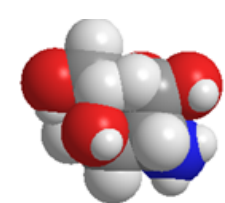

(B)
Fig. 2. D - ( +) - Glucosamine representations: (A) hexagonal, (B) 3D (red : oxygen; black : carbon; white : hydrogen; blue : nitrogen) (Space Filling).

Glucosamine is a glycosylated amine. This is a normal constituent of cartilage that would act by stimulating and normalizing the biosynthesis of proteoglycans of the articular cartilage, inhibiting certain enzymes that destroy cartilage and reducing superoxide radicals that damage tissues [6], glucosamine is a precursor used for the glycosylation of proteins and lipids ... etc .

There are two forms of glucosamine differ from their substituents which are: glucosamine hydrochloride and glucosamine sulfate (see Fig. 3) [7].

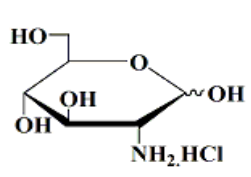

Glucosamine hydrochloride

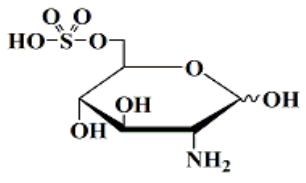

Glucosamine sulphate

Fig. 3. Representation of (+)-D-Glucosamine- $\mathrm{HCl}$ and (+)-D-Glucosamine- $\mathrm{SO}_{3} \mathrm{H}$.
Chemical modification of Glucosamine offers both enormous opportunities and real challenges for chemists. Modifying Glucosamine can indeed help to improve their physicochemical and pharmacological properties.

It is also a way to create original molecules with specific functions, finding various applications beyond the borders of classical chemistry. The challenge facing chemists is to develop effective methods to selectively protect the four alcohol functions and the amine function carried by the glucosamine.

The primary amines are more reactive and less stable because the amino group has one electron pair, which may be 
protonated or reacted with electrophiles.

To make them less reactive the amine can be converted to an amide in the presence of t-butoxycarbonyl (Boc).

The clevage $\mathrm{NH}$-Boc can be achieved for example by using a strong acid $\mathrm{CF}_{3} \mathrm{CO}_{2} \mathrm{H}$ (TFA) [8], [9] or by using a chemically inert catalyst such as kaolin of Clay (KC) [10] requires a lot of time with a very low yields by against the clevage by microwave gives good yields in very short times .

The irradiation of the reactional mediums by the microwaves is a technique increasingly used in organic syntheses. The first organic syntheses carried out in a domestic furnace were described in 1986 [11] by Gedye and Giguere. Today, the number of publications in this field does not cease increasing exponentially [12], [13]. Several authors work in absence of solvent.

The interest to operate without solvent is known for a long time, it relates to the reactivity and sometimes the selectivity of the reactions. The principle is based on the impregnation of the reagents on supports or a simple mixture of reagents with a solid, liquid catalyst or of transfer of phase. The coupling with microwaves makes it possible to operate in full safety with atmospheric pressure in all types of furnaces [14].

The heat transfer under heating microwaves is completely reversed compared to the conventional heating. The traditional heat transfer is transmitted of the outside to the interior of the recipient. Under heating microwave, treated volume becomes him even source of heat. We speak about release of heat for the interior to the outside of the recipient. The external wall of the reactor is colder than the medium of the reactor in the case of the heating microwave, and conversely for the case of the conventional heating by dual envelope, hotplate and flame. It is a mode of instantaneous heating in volume and not on the surface. The thermal phenomena of conduction and convection play a secondary part of equilibrium for the temperature. Local over heating can also occur (see Fig. 4) [15].

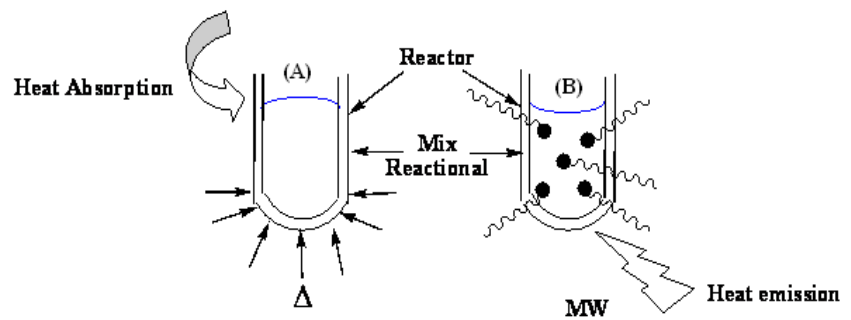

Fig. 4. Gradients in temperature for materials submitted either to traditional (A), or to microwave radiation (B).

Instantaneous character of the heating led to reactions much faster and a weak degradation of the products. Many chemical syntheses use solvents organic, expensive, toxic, non which can be recycled and thus generators of pollution. Thus, the benzene is interdict of employment on an industrial scale, and the use sometimes, of strong mineral acids poses problems of safety. Lastly, the dilution of the reagents lowers the yield and increases considerably the reaction time [16]. (Yield: fraction of reagents having reacted compared to the concerned reagents).

To free itself from solvents thus constitutes an essential objective. This is why the techniques of reaction without solvent developed. It can be a simple mixture of reagents without catalyst [17].
The reaction can proceed if one of the reagents is liquid and if the other reagents are solid, they are soluble in this liquid. Other reactions can, in certain cases, being realized gratitude to the use of mineral supports solid not toxic and which can be recycled like alumina, the silica gels or clay [18], [19].

With the molecular scale, the most polished surface even of a solid is irregular and present cavities. The liquid penetrates in these cavities (adsorption). Its reactivity is strongly increased and the reaction is started with the liquid interface/wall of the cavity. Lastly, a third technique requires the use of inexpensive catalysts making it possible the reaction to always be done without solvent. It is the catalysis by transfer of phase (CTP) solid-liquid without solvent [20], [21].

\section{EXPERIMENTAL SECTION}

\section{A. Generals Conditions}

\section{1) Products}

$\mathrm{KBr}$ (IR), 98\% Acetic Anhydride, 98\% KOH, 37\% $\mathrm{HCl}$, (+)-D-Glucosamine hydrochloride ((+)-D-GlucNH $\left.\mathrm{N}_{2} \cdot \mathrm{HCl}\right)$, from Aldrich Chemical Company, Ethyl acetate (AOEt), Tertbutydicrbonyle (Boc) $)_{2} \mathrm{O}$, silica gel, sulfate sodium $\left(\mathrm{Na}_{2} \mathrm{SO}_{4}\right)$, sodium bicarbonate $\left(\mathrm{Na}_{2} \mathrm{CO}_{3}\right)$

2) Solvents

Methanol $99 \%$ and/ or Ethanol $99.8 \%$, 99.9\% Dichloromethane, Dioxane $99.78 \%$, distilled water, Hexane, Citric acid, Acetone, Pyridine, DMAP (4-dimethylaminopyridine).

\section{B. Characterization Methods}

TLC: The thin layer chromatography was performed on silica plates Merck 60 F354 (Art. 5554).

NMR: The NMR spectra were recorded with a Bruker (Forward) to $400.13 \mathrm{MHz}$, for ${ }^{1} \mathrm{H}$ NMR, and $100.61 \mathrm{MHz}$ for ${ }^{13} \mathrm{C}$ NMR .

The tetraméthylsilane (TMS) is used as internal reference. Chemical shifts for spectra in $\mathrm{D}_{2} \mathrm{O}, \mathrm{CDCl}_{3}$ or DMSO- $\mathrm{d}^{6}$ are given in ppm.

Mass spectrometry (MS): Measurements of fast atomic bombardment - mass spectrometry (Matrix: NBA, FABMS) are performed with Auto Spec M (Micromass). The samples were prepared by solution in Meta Nitrophenol.

Infrared Fourier Transform: The FTIR spectra were obtained with a spectrometer Bruker IFS 66/5 from KBr pellets.

In this work, we developed the deprotetion of glucosamine ( $N \mathrm{H}$ - Boc Acyle glucosamine $\left(a_{1}\right)$ ) by irradiation microwave to form $\mathrm{NH}_{2}$-Glucosamine Acyle $\left(a_{2}\right)$. Total protection was carried out in two stages starting from commercial glucosamine: The protection of the function amine is carried out by Di-tert-Butyl carbonates (Boc) $)_{2} \mathrm{O}$ in basic medium, this stage makes it possible to release the amine and to graft Boc, we reaches easily (the $\mathrm{NH}-\mathrm{Boc}$ under microwave, the chimioselective deprotection and we reaches $\mathrm{NH}_{2}-$ Glucosamine tetra-acetyl $\left(a_{2}\right)$ easily. All the reactions are carried out under argon. Their advance is controlled by TLC and the revelation by a solution of $\mathrm{H}_{2} \mathrm{SO}_{4}$ with (10\%), sugars appear in the form of brown spot on TLC.

The purifications are carried out on column of 
chromatography on silica gel $(35 \mu \mathrm{m}-70 \mu \mathrm{m})$. The purity of the products is controlled by analysis ${ }^{1} \mathrm{H}$ NMR, IR, by mass spectrometry in chemical mode ionization ESI and by the measurement of the melting point by Electrothermale (BI).

Stage 1: The protection of the function amine by (Boc) $)_{2} \mathrm{O}$ Synthesis of 2-Desoxy-2-N-Tertiobutyloxycarbonyl Glucose $\left(a_{1}\right)$

In a balloon of $250 \mathrm{~mL}$, 1eq of 2-Desoxy-2-amino-glucose $(10 \mathrm{~g} ; 49,7 \mathrm{mmol})$ is solubilized in $150 \mathrm{~mL}$ of a mixture of Dioxane and a solution of Potassium hydroxide $1 \mathrm{~N}(1 / 1)$ (Dioxane/KOH). To the solution is added 2 eq of $(\mathrm{Boc})_{2} \mathrm{O}(15$, $2 \mathrm{~g} ; 99,5 \mathrm{mmol})$, the solution is left under agitation at room temperature. At the end of three hours of agitation, a precipitate was formed, this one is filtered then washed with a mixture of water/dioxane, the product of the reaction is obtained in the form of a white powder (see Fig. 5).
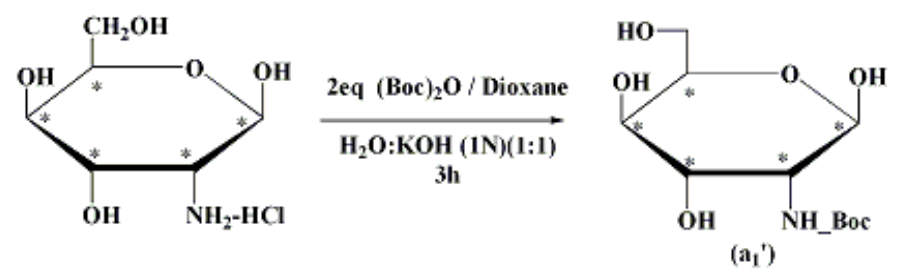

Fig. 5. The protection of the function amine by $(\mathrm{Boc})_{2} \mathrm{O}$.

Results and Discussion:

The recrystallization is carried out by mixture of three solvent $\left(\mathrm{MeOH} /\right.$ Dioxane $\left./ \mathrm{H}_{2} \mathrm{O}\right)(50: 25: 25)$ until the formation of the beautiful white crystals, their melting points $\mathrm{T}=$ $194^{\circ} \mathrm{C}-195^{\circ} \mathrm{C}, 95 \%$ yield, $\mathrm{TLC}\left(\mathrm{R}_{\mathrm{F}}=0,2\left[\mathrm{AOEt} / \mathrm{H}_{2} \mathrm{Cl}_{2}\right.\right.$ : v/v ; 8:2) ]; $[\alpha]:+64^{\circ}(\mathrm{C}=4,7 ; \mathrm{MeOH}) .{ }^{1} \mathrm{H}$ NMR (DMSO, $\mathrm{d}^{6}$, $250 \mathrm{MHz}) \delta(\mathrm{ppm}) ; 4,96\left(\mathrm{~d}, 1 \mathrm{H}, \mathrm{H} 1, \mathrm{~J}_{\mathrm{H} 1-\mathrm{H} 2}=3,4 \mathrm{~Hz}\right) ; 3,4-3,65$ (m, 4H, H3, H6, H6') ; $3-3,4$ (m, 2H, H2, H5) ; 1,35 (s, 9H, Boc).

Mass (Matrix: GT ; $\left.\mathrm{FAB}^{+}\right): 280[\mathrm{M}+\mathrm{H}]^{+} ; 206([\mathrm{M}$ $\left.\mathrm{OC}\left(\mathrm{CH}_{3}\right)_{3}\right]^{+}$.

Stage 2: The protection of all alcohols functions by acetic Anhydride

1) Synthesis of

2-Desoxy-2-N-Tertiobutyloxycarbonyl-2-3-4-6-Tetra-Acet ylglucose $\left(\mathrm{a}_{1} "\right)$

leq of made up $\mathrm{NH}$-Boc-Glucosamine $(2.5 \mathrm{~g}, 9.43 \mathrm{Mmol})$ is solubilized in $10 \mathrm{~mL}$ of pyridine, a catalytic quantity of 4Dimethylaminopyridine (DMAP) is added to the solution, and this one is cooled with $0^{\circ} \mathrm{C}$. Then added, drop-by-drop 4eq of acetic Anhydride $(7.6 \mathrm{~mL}, 0.075 \mathrm{Mmol})$ diluted in pyridine $5 \mathrm{~mL}$.
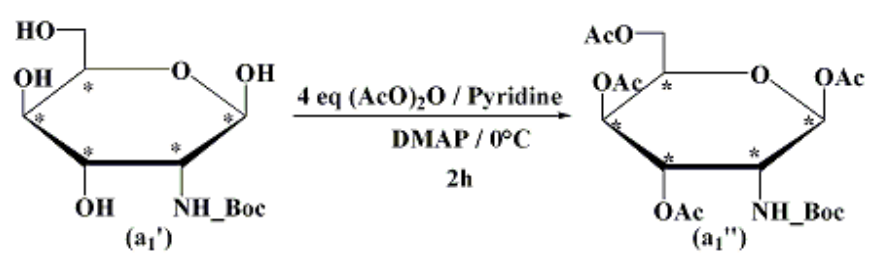

Fig. 6. Protection of all alcohols functions by acetic Anhydride.

At the end of three hours of agitation at ambient temperature, the reactional mixture is diluted in $200 \mathrm{~mL}$ of one aqueous solution frozen of $\mathrm{NaHO}_{3}$ with $(3 \%)$; then the phase aqueous and extracted three times with $100 \mathrm{~mL}$ from $\mathrm{CH}_{2} \mathrm{Cl}_{2}$, the organic phase are gathered, washed with a citric solution of acid ( $5 \%$ ), then with water, the organic phase is then dried by sodium sulphate $\mathrm{Na}_{2} \mathrm{SO}_{4}$, solvent is evaporated under vacuum, the reactional mixture is then purified by chromatography on silica gel column whereas using like leant the system ([AOEt / Hexane : V/V ; 3:7) ]). 98\% yield (see Fig. 6)

Results and Discussion:

TLC $\left(\mathrm{R}_{\mathrm{f}}=0,5\right.$ [ AOEt $/$ Hexane : v/v ; 1:1)]. $\mathrm{F}=67^{\circ} \mathrm{C}-70^{\circ} \mathrm{C}$. $[\alpha]:+67^{\circ}\left(\mathrm{C}=0,15 ; \mathrm{HCl}_{3}\right) .{ }^{1} \mathrm{H} \mathrm{RMN} \quad\left(\mathrm{DCl}_{3}, 250 \mathrm{MHz}\right) \delta$ $(\mathrm{ppm}) ; 6,12\left(\mathrm{~d}, 1 \mathrm{H}, \mathrm{H} 1, \mathrm{~J}_{\mathrm{H} 1-\mathrm{H} 2}=3,48 \mathrm{~Hz}\right) ; 5,05-5,17(\mathrm{~m}, 2 \mathrm{H}$, $\mathrm{H} 3$ and $\mathrm{H} 4) ; 4,2\left(\mathrm{dd}, 1 \mathrm{H}, \mathrm{H} 6, \mathrm{~J}_{\mathrm{H} 6-\mathrm{H} 6},=4 \mathrm{~Hz}, \mathrm{~J}_{\mathrm{H} 6-\mathrm{H} 5}=12,42 \mathrm{~Hz}\right)$; 3,58 - 4,25 (m, 3H, H2, H5 and H6); 1,95 - 2,12 (s, 12H, $\left.\mathrm{AcO}_{2}\right) .{ }^{13} \mathrm{C} \mathrm{RMN}\left(\mathrm{DCl}_{3}, 200 \mathrm{MHz}\right) \delta(\mathrm{ppm}) ; 91,10(\mathrm{C} 1)$; 71,05 (C3); 69,72 (C5); 67,82 (C4); 61,67 (C6); 52,26 (C2);

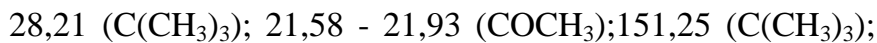
$154,90(\mathrm{NHCO}) ; 168,70-171,13\left(\mathrm{COCH}_{3}\right)$. Masse (Matrix : $\left.\mathrm{NBA} ; \mathrm{FAB}^{+}\right): 348[\mathrm{M}+\mathrm{H}]^{+} ; 370[\mathrm{M}+\mathrm{Na}]^{+} ; 289[\mathrm{M}-$ AC-OH-H $]^{+} ; 246$ [M-AcO-OH-Ac].

Stage 3: The deportation by the use of Microwave new method use the modern heating by magnetic waves "Micro-Wave" (MW)

In a domestic Microwave of (70 W to $600 \mathrm{~W}) \mathrm{LG}$ marks, in a erylen $50 \mathrm{~mL}$ poses $0.5 \mathrm{~g} \mathrm{NH}$-Boc-Glucosamine-Ac, we adds mineral solid supports, the reactional mixture is left during 1 min with 350 Watt until the end of the reaction, evolution of the reaction is followed by TLC, which shows the polar formation of one produced revealed in Ninhydrine (see Fig. 7).
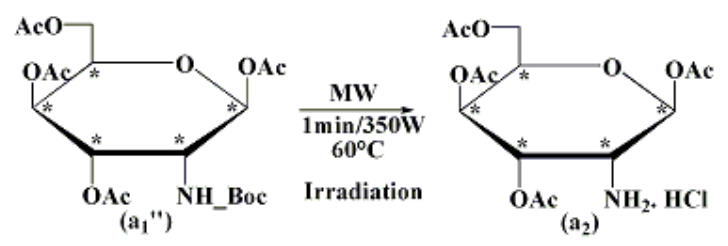

Fig. 7. Deportation by the use of microwave.

Results and Discussion:

The precipitated product is filtered by ether to lead a white powder in 90\% yield. TLC: $\mathrm{R}_{\mathrm{f}}=0,4$ [AOEt / $\mathrm{H}_{2} \mathrm{Cl}_{2}$. v/v; 8:2] ${ }^{1} \mathrm{H}$ NMR (DMSO, d $\left.{ }^{6}, 250 \mathrm{MHz}\right) \delta(\mathrm{ppm}) ; 6,2(\mathrm{~d}, 1 \mathrm{H}, \mathrm{H} 1$, $\left.\mathrm{J}_{\mathrm{H} 1-\mathrm{H} 2}=3,62 \mathrm{~Hz}\right) ; 5,25\left(\mathrm{dd}, 1 \mathrm{H}, \mathrm{H} 3, \mathrm{~J}_{\mathrm{H} 2-\mathrm{H} 3}=9,89 \mathrm{~Hz}, \mathrm{~J}_{\mathrm{H} 3-\mathrm{H} 4}=\right.$ $9,73 \mathrm{~Hz}) ; 4,92\left(\mathrm{dd}, 1 \mathrm{H}, \mathrm{H} 4, \mathrm{~J}_{\mathrm{H} 4-\mathrm{H} 5}=9,38 \mathrm{~Hz}\right) ; 4,12-4,20(\mathrm{~m}$, 2H, H6, H6'); $(3,5-3,85)$ (m, 2H,H5,H2). ${ }^{13} \mathrm{C}$ NMR (DMSO, $\left.\mathrm{d}^{6}, 200 \mathrm{MHz}\right) \delta(\mathrm{ppm}) ; 89,01(\mathrm{C} 1) ; 71,02(\mathrm{C} 3) ; 70,59(\mathrm{C} 5)$; 69,72 (C4); 61,87 (C6); 51,01 (C2); 21,16-21,94 ( $\left.\mathrm{COCH}_{3}\right)$; $169,53-170,84\left(\mathrm{COCH}_{3}\right)$.

\begin{tabular}{cccc}
\multicolumn{3}{c}{ TABLE I: COMPARISON BETWEEN THE DEPROTECTION By MiCROWAVES, } \\
DEPROTECTION BY THE TFA AND DEPROTECTION BY CATALYZE
\end{tabular}

The results are summarized in Table I. The reaction is quantitative under microwaves in 1minute with power of $350 \mathrm{~W}$, whereas the reaction time with the use of the TFA (Trifluoroacetic Acid) and kaolin of Clay (KC) is very important. 


\section{CONCLUSION}

At this contribution on the interest of the microwaves in organic synthesis, we understand better why electrothermics microwave is a technology in full rise. Obviously, this technology fulfills perfectly well the requirements of today which are the speed and the effectiveness. The deprotection by the use of microwave aims to the modernization and the simplification of the processes and to make them less polluting.

\section{ACKNOWLEDGEMENT}

The compounds obtained with good yields can be used as precursors in the design of bioactive entities and others by addition or nucleophilic substitution to lead to the analogues glucosamine models. This work can be supplemented by a toxicological study, kinetics of decomposition in physiological medium and others evaluations pharmacological in vivo and in vitro.

\section{REFERENCES}

[1] I. W. Southon and J. Buckingham, Dictionary of Alkaloids, Chapman \& Hall, New York, 1989.

[2] K. V. Gothelf and K. A. Jørgensen, Chem. Rev., vol. 98, pp. 863-870, 1998.

[3] A. Brandi, S. Cicchi, F. M. Cordero, A. Goti, Chem. Rev., vol. 103, p. 1213, 2003.

[4] C. Prouvost and S. Laverty, Prat.Vét. Equine, vol. 32, p. 31, 2000.

[5] G. C. Losrreyes, R. T. Koda, and E. J. Lien, Prog. Drug. Res., vol. 55, p. 81,2000

[6] J. Couture, "L'utilisation de la glucosamine pour traiter l'arthrose," Le Médecin du Québec, vol. 36, no. 9, pp. 75-79, 2001.

[7] G. X. Qiu, X. S. Weng, K. Zhang, Y. X. Zhou, S. Q. Lou, Y. P.Wang, W. Liu, H. Zhang, and Y. Liu, "A multi-central, randomized, controlled clinical trial of glucosamine hydrochloride/sulfate in the treatment of knee osteoarthritis," Zhonghua Yi Xue Za Zhi (Chinese), vol. 85, pp. 3067-3070, 2005.

[8] E. A. Englund, H. N. Gopi, and D. H. Appella, Org. Lett, vol. 6, pp. 213-215, 2004.

[9] D. M. Shendage, R. Froehlich and G. Haufe, Org. Lett, vol. 6, pp. 3675-3678, 2004.

[10] M. Larhed and A. Hallberg, "Microwave-assisted high-speed chemistry a new technique in drug discovery," Drug Discovery Today, vol. 6, no. 8, pp. 406-416, 2001.
[11] R. Gedye, F. Smith, K. Westaway, A. Humera, L. Baldisera, L. Laberge, and J. Rousell, "The use of microwave ovens for rapid organic synthesis," Tetrahedron Letters, vol. 27, issue 3, pp. 279-282, 1986.

[12] A. Stadler, B. H. Yousefi , D. Dallinger, P. Walla, E. Vander Eycken, N. Kaval, and C. O. Kappe, Org. Process Res Dev, vol. 7, pp. 707-716, 2003.

[13] N. Kaval, W. Dehaen, C. O. Kappe, and E. Vander, "The effect of pressure on microwave-enhanced Diels-Alder reactions: A case study," Org. Biomol. Chem, vol. 2, pp. 154-156, 2004.

[14] C. O. Kappe, "Controlled microwave heating in modern organic synthesis," Angew Chem Int Ed, vol. 43, pp. 6250- 6284, 2004.

[15] J. Thuery, "Les micro-ondes et leurs effets sur la matière," Thec \& Doc, Lavoisier, Paris, 1989.

[16] D. M. P. Mingos and D. R. Baghurst, Chem. Soc. Rev, vol. 20, pp. 1- 47, 1991.

[17] J. Jacob, "Microwave assisted reactions in organic chemistry: A Review of recent advances," International Journal of Chemistry, vol. 4, pp. 29-43, 2012.

[18] S. Caddick, "Microwave assisted organic reactions," J. Tetrahedron, vol. 51, pp. 10403-10432, 1995.

[19] C. O. Kappe and A. Stadler, Microwaves in Organic and Medicinal Chemistry, Wiley-VCh, 2005.

[20] C. O. Kappe, Microwaves in Combinatorial and High-Throughput Synthesis, Kluwer Academic Publishers, 2003.

[21] F. Langa, "Microwave irradiation: More than just a method for accelerating reactions, contemp," Org. Synth, vol. 4, no. 5, pp. 373-386, 1997.

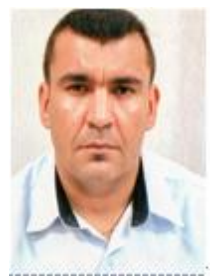

Hocine Bouleghlem was born on November 30, 1975 in Skikda. He has been an assistant master in organic chemistry and research professor at the University of Mohamed Boudiaf, Msila Algeria since 2007.

He has some publication: H. Bouleghlem, M Berredjem, M. Lecouvey and N. E. Aouf, "New pseudonucleosides containing chiral oxazolidin-2-ones and cyclosulfamides as aglycones: Synthesis and antiviral evaluation," Nucleosides, Nucleotides And Nucleic Acids, vol. 26, issue 10-12, pp. 1539 -1942, Dec 2007. M. Ibrahim-Ouali, H. Bouleghlem, and R. Eugenie, "First total syntheses of ( \pm -3-aza-11-selena and ( \pm )-3-aza-11-tellura steroids," Tetrahedron, vol. 67, no. 20, pp. 3668 -3676, May 2011. M. Ibrahim-Ouali, H. Bouleghlem, and N. E. Aouf, "Ring-closing metathesis towards functionalised pentacyclic steroids," Tetrahedron Letters, vol. 53, issue 14, pp. 1859-1862, April 2012.

Mr. Hocine is a member in the Research Laboratory of Organic Chemistry Applied (LCOA), Group of Chemistry Bioorganique, Faculty of Science, Department of Chemistry, University Badji-Mokhtar 23000 Annaba, Algeria and a member of the research project: (Synthesis and Bioactive Molecules Development) under code $N^{\circ} \mathrm{E} 01120070109$. 